\title{
Metabolic Syndrome in People Living with HIV in Lome (Togo): Epidemiological Aspects and Associated Factors
}

\author{
Abdou Razak Moukaila1,2,3* ${ }^{\mathbb{D}}$, Edem Komi Mossi1,2, Mouhaman-Inouwa Kpelafia4, \\ Komi Dzidzonu Nemi', Kossi Kodjo', Agbeko Kodjo Djagadou', Lidaw Déassoua Bawe3, \\ Akessiwe Akouda Patassi ${ }^{3}$, Yawovi Mawufemo Tsevi5, Ihou Majesté Wateba ${ }^{3}$, \\ Awalou Mohaman Djibril1
}

\footnotetext{
${ }^{1}$ Department of Internal Medecine, Sylvanus Olympio University Hospital, University of Lome, Lome, Togo

${ }^{2}$ Diabetes Academic Afrique, Lome, Togo

${ }^{3}$ Department of Infectious and Tropical Diseases, Sylvanus Olympio University Hospital, University of Lome, Lome, Togo ${ }^{4}$ Department of Cardiology, Campus University Hospital, University of Lome, Lome, Togo

${ }^{5}$ Department of Nephrology and Hemodialysis, Sylvanus Olympio University Hospital, University of Lome, Lome, Togo

Email: *moukaila.razak@gmail.com
}

How to cite this paper: Moukaila, A.R., Mossi, E.K., Kpelafia, M.-I., Nemi, K.D., Kodjo, K., Djagadou, A.K., Bawe, L.D., Patassi, A.A., Tsevi, Y.M., Wateba, I.M. and Djibril, A.M. (2020) Metabolic Syndrome in People Living with HIV in Lome (Togo): Epidemiological Aspects and Associated Factors. Open Journal of Endocrine and Metabolic Diseases, 10, 59-75.

https://doi.org/10.4236/ojemd.2020.104007

Received: March 1, 2020

Accepted: April 14, 2020

Published: April 17, 2020

Copyright ( 2020 by author(s) and Scientific Research Publishing Inc. This work is licensed under the Creative Commons Attribution International License (CC BY 4.0).

http://creativecommons.org/licenses/by/4.0/ (c) (i) Open Access

\begin{abstract}
Introduction: People living with HIV (PLWHIV) are exposed to Metabolic Syndrome (MS), which increases their risk of having cardiovascular events and type 2 diabetes. No data on this subject is available in Togo. Objective: The objective of our study was to make an inventory of the metabolic syndrome among PLWHIV in Togo. Method: This was a prospective cross-sectional descriptive and analytical study on PLWHIV received at the day hospital of the Infectious Diseases Department of the Sylvanus Olympio University Hospital for a period of six months. Results: A total of 279 PLWHIV patients were enrolled, of which 237 (84.9\%) were on Highly Active Antiretroviral Treatment (HAART) and $42(15.1 \%)$ were naive. Metabolic syndrome has been demonstrated in $28.7 \%$ of the study population. Abdominal obesity was the most represented component of MS with a proportion of 57.7\%. Risk factors associated with MS were female sex (OR = 3.01; CI: 1.52 - 5.93; p < 0.001 ), body mass index $\geq 25 \mathrm{Kg} / \mathrm{m}^{2}$ (OR = 3.29; CI: 1.92 - 5.64; $\left.\mathrm{p}<0.001\right)$, HDL hypocholesterolemia (OR = 12.24; CI: $5.78-25.89$; $\mathrm{p}<0.001$ ), hypertriglyceridemia $(\mathrm{OR}=5.09$; CI: $2.40-10.79 ; \mathrm{p}<0.01)$, hyperglycemia $(\mathrm{OR}=$ 3.39; CI: $1.82-6.30 ; \mathrm{p}<0.024)$, LDL hypercholesterolemia (OR = 2.04; CI: 1.17 - 3.56; $\mathrm{p}<0.012$ ), CD4 count $\geq 500 \mathrm{cel} / \mathrm{mm}^{3}$ (OR = 1.85; CI: $1.06-3.20$;
\end{abstract}


$\mathrm{p}<0.029)$, high blood pressure $(\mathrm{OR}=13.04$; CI: $6.16-27.62 ; \mathrm{p}<0.001)$.

Conclusion: There is a need to screen MS for PLWHIV so that risk factors associated with it can be addressed early.

\section{Keywords}

HIV, HAART, Metabolic Syndrome, Dyslipidemia, Hypertension, Hyperglycemia, Togo

\section{Introduction}

At the end of 2018, 37.9 million people were living with HIV worldwide [1]. At the same period Africa had the higher prevalence with two-third (2/3) of PLWHIV [1]. According World Health Organization data, $62 \%$ of adults living with HIV in low-income countries had access to HAART in 2018 [1]. Thanks to intensified screening and improved accessibility to HAART, the life expectancy of PLWHIV is now increasing and the HIV pandemic has declined dramatically with a reduction in the number of deaths of more than $56 \%$ since the peak in 2004 [2]. Unfortunately, HAART expose them to many metabolic disorders which enhance their cardiovascular disease risk [3]. So, dyslipidemia, fat distribution disorders will be favored by HAART [3]. HIV itself, will induce an immune response with synthesis of proinflammatory cytokines [4] leading to a chronic inflammation. This chronic inflammation secondarily will lead to atherosclerosis and a reduction in the synthesis of adiponectin, which is known to promote the action of insulin in the skeletal muscle [4]. Hyperglycemia can thus secondarily develop as a result of insulin resistance, which can lead to type $2 \mathrm{di}$ abetes. In addition, studies have also reported the likely diabetogenic effect of protease inhibitors by inhibiting GLUT 4 receptors, insulin-sensitive receptors in muscle and adipose tissue [5] [6] [7]. These metabolic disturbances expose PLWHIV at risk of metabolic syndrome (MS). MS is diagnosed based on the presence of at least three of five components of a cluster of cardiovascular diseases risk factors, namely: abdominal obesity, high triglyceride levels in the blood, a decrease in HDL cholesterol, high blood pressure, and high blood sugar [8]. The prevalence of MS among PLWHIV is estimated to be between $7 \%$ and $45 \%$ [9]. No study in Togo has yet addressed the issue of MS among PLWHIV.

In Togo, the average prevalence of HIV infection in 2017 in the general population aged 15 to 49 years was estimated at $2.1 \%$ [10]. A recent study in Togo estimated the prevalence of dyslipidemia among HAART patients to $72.5 \%$ [11]. In order to provide data that will contribute to improving the medical management of PLWHIV in Togo, in particular in the prevention of cardiovascular events to which this layer of the population is exposed in connection with the metabolic syndrome, we initiated this work whose objective was to assess the MS and its associated risk factors in PLWHIV. 


\section{Patients and Methods}

\subsection{Presentation of the Study Site}

Our study took place at the Ambulatory Treatment Center (CTA) of the Infectious Diseases Department of the Sylvanus Olympio University Hospital in Lomé (CHU-SO). It is the reference service for the care of PLWHIV in Togo. The active queue for this service is approximately 3528 patients who are regularly followed on HAART.

\subsection{Type and Period of Study}

We conducted a prospective, descriptive, cross-sectional and analytical study on HAART patients received in consultation for their routine follow-up and newly diagnosed PLWHIV received for initiation of their HAART during the period from March 1 to August 30, 2019 i.e. a period of six month.

\subsection{Study Population}

The inclusion criterias in our study were:

- Any PLWHIV on HAART received in a follow-up consultation during the study period, who is over 18 years of age, who has been regularly followed for at least six months at the CTA of the SO University Hospital and who has not missed any follow-up appointment in the six months preceding the day of his or her consultation.

- Any PLWHIV naive to HAART, received for HAART initiation consultation.

- Have the results of a blood test no more than three months old consisting of a serum assay of total cholesterol (CT), triglycerides (TG), HDL-cholesterol (HDL-c), LDL-Cholesterol (LDL)-c), CD4 count (CD4).

The following were excluded from our study:

- Any patient presenting a situation that could lead to an increase in abdominal volume and distort the measurement of waist circumference (pregnant woman, liver pathology with ascites).

- Breastfeeding women.

- Patients who refused to participate in the study.

\subsection{Sampling Method}

Patients on HAART were randomly recruited during follow-up visits with a maximum of ten patients per week throughout the study period. All naive patients meeting the inclusion criteria were retained.

\subsection{Definitions of Metabolic Syndrome}

Since its introduction, the MS has been defined in various ways [12]. The most widely used definitions for MS come from the International Diabetes Federation (IDF) and the American Heart Association/National Heart, Lung, and Blood Institute (AHA/NHLBI). However, among PLWHIV there was a debate about patient's classification based on these two definitions [13]. In order to harmonize 
the definitions, IDF and AHA/NHLBI agreed on a common definition, which was used in our study [12].

Based on the criteria of the Adult Treatment Panel III (ATPIII) [12], MS was defined as the presence of at least three of the following: 1) waist circumference $>88 \mathrm{~cm}$ in women or $>94 \mathrm{~cm}$ in men; 2) systolic blood pressure (SBP) $\geq$ $130 \mathrm{~mm} \mathrm{Hg}$ or diastolic blood pressure (DBP) $\geq 85 \mathrm{~mm} \mathrm{Hg}$ or the use of antihypertensive medication; 3 ) triglyceridemia $\geq 150 \mathrm{mg} / \mathrm{dL}$ or use of a lipid-lowering medication (niacin, fenofibrate and gemfibrozil); 4) fasting blood glucose $\geq 100$ $\mathrm{mg} / \mathrm{dL}$, doctor's diagnosis of diabetes or use of diabetes medication; 5) high density lipoprotein cholesterol (HDL) $<50 \mathrm{mg} / \mathrm{dL}$ in women or $<40 \mathrm{mg} / \mathrm{dL}$ in men.

\subsection{Data Collection}

A data collection sheet was designed and used as the basis for data collection. Patients were informed in advance of the data collecting process. The data collected were: 1) socio-demographic data, age, sex; 2) history of pre-existing high blood pressure (hypertension) or current antihypertensive treatment, the existence of known diabetes with or without treatment, alcohol consumption, active smoking; 3) HIV infection data, i.e., length of time on HAART, current HAART protocol; 4) anthropometric data; 5) data from follow-up analyzes of TxCD4, determination of CT, TG, HDL-c dosage. The LDL-c was calculated from the Friedwald formula according to the formula: $\mathrm{LDL}-\mathrm{C}=\mathrm{CT}-(\mathrm{HDL}-\mathrm{C}+\mathrm{TG} / 5)$.

\subsection{Data Sources}

Age, gender, notions of hypertension and diabetes, history of HIV, were collected by interview and via the treatment file.

Waist circumference was measured with a tape measure surrounding the waist by the midpoint between the lower edge of the rib and the iliac crest in a plane perpendicular to the major axis of the body.

The size was determined without shoes using a height rod. The weight was measured using a scale. The body mass index (BMI) was calculated based on the ratio of weight to height squared. A BMI greater than $25 \mathrm{~kg} / \mathrm{m}^{2}$ defined overweight.

High waist circumference has been defined according to the criteria of the International Diabetes Federation (waist circumference greater than or equal to 94 $\mathrm{cm}$ in men and greater than $88 \mathrm{~cm}$ in women).

Every six months, each HAART patient is asked to have an immunological and biochemical check-up and a viral load test each year. Only the immunologi$\mathrm{cal}$ and virological assessment is subsidized. We therefore take advantage of the results of these analyzes to collect the information from the analyzes.

Lipid fraction disorders met the definitions of the National Cholesterol Education Program, Adult Treatment Panel III criteria which are: total hypercholesterolemia (HCT) if total cholesterol greater than or equal to $2 \mathrm{~g} / \mathrm{L}$, hypertriglyceridemia (HTG) if triglyceridemia greater than or equal to $1.5 \mathrm{~g} / \mathrm{L}$, HDL hypo- 
cholesterolemia $(\mathrm{HCH})$ if HDL cholesterol less than $0.5 \mathrm{~g} / \mathrm{L}$ in women and less than $0.4 \mathrm{~g} / \mathrm{L}$ in men, LDL hypercholesterolemia (HCL) if LDL cholesterol greater than or equal to $1.3 \mathrm{~g} / \mathrm{L}$. The atherogenicity index was assessed on the basis of the CT/HDL ratios, which is a revealing indicator of arterial and especially coronary risk. If the $\mathrm{CT} / \mathrm{HDL}$ ratio is $\geq 5$ the atherogenic risk was considered to be statistically significant.

\subsection{Statistical Data Analysis}

All the data were entered in a data entry mask developed in Epi data version 3.1 software and then analyzed using the IBM SPSS Statistics 20 statistical software.

The data were analyzed using the Chi2 test or Fisher's exact test to compare the proportions of the qualitative variables. Quantitative variables were compared using Student's t test or the Mann-Whitney U test depending on whether they followed a normal distribution or not. Univariate and multivariate binary logistic regression analysis was used to assess factors associated with the presence of MS; the logistic regression models' results are presented as odds ratios (OR) with the $95 \%$ CI. A p-value $<0.05$ was considered statistically significant.

\subsection{Ethical Considerations}

The authorization of the head of the Ambulatory Treatment Center for HIV-infected people has been obtained. Informed consent was obtained from patients. The anonymity and confidentiality of the results were respected.

\section{Results}

\subsection{General Characteristics of the Study Population}

A total of 279 PLWHIV were included in our study, of which 237 (84.9\%) were on HAART and 42 (15.1\%) were naive (Table 1).

Table 1. Socio demographic, anthropometric and HIV infection characteristics of the study population.

\begin{tabular}{cc}
\hline Characteristics & Values \\
\hline Age (Years), mean \pm SD & $47.73 \pm 9.3$ \\
Gender, n (\%) & \\
Male & $81(29.9)$ \\
Female & $198(70.1)$ \\
Occupation, n (\%) & \\
Traders & $129(46.2)$ \\
Government employers & $34(12.2)$ \\
Crafts & $32(11.5)$ \\
Unemployed & $25(9.0)$ \\
Retirees & $21(7.5)$ \\
Employees in the private sector & $18(6.4)$ \\
\hline
\end{tabular}




\section{Continued}

\begin{tabular}{|c|c|}
\hline & \\
\hline Farmers & $10(3.6)$ \\
\hline Students & $10(3.6)$ \\
\hline \multicolumn{2}{|l|}{ Marital status, n (\%) } \\
\hline Married & $138(49.5)$ \\
\hline Widowed living alone & $53(19.0)$ \\
\hline Single & $50(17.9)$ \\
\hline Divorced & $36(12.9)$ \\
\hline Widowed remarried & $2(0.7)$ \\
\hline \multicolumn{2}{|l|}{ Education level, n (\%) } \\
\hline None & $78(28.0)$ \\
\hline Primary & $87(31.2)$ \\
\hline Secondary & $76(27.2)$ \\
\hline Higher study & $12(4.3)$ \\
\hline Alcohol consumer, n (\%) & $82(29.4)$ \\
\hline Smoker, n (\%) & $14(5.0)$ \\
\hline $\mathrm{BMI}\left[\mathrm{Kg} / \mathrm{m}^{2}(\mathrm{IQR})\right]$ & $23.3(20.6-27.3)$ \\
\hline $\mathrm{BMI} \geq 25 \mathrm{Kg} / \mathrm{m}^{2}, \mathrm{n}(\%)$ & $104(37.3)$ \\
\hline \multicolumn{2}{|l|}{ Waist circumference $(\mathrm{cm})$, mean \pm SD } \\
\hline Male & $83.9 \pm 8.0$ \\
\hline Female & $87.9 \pm 11.7$ \\
\hline \multicolumn{2}{|l|}{ HAART exposure, n (\%) } \\
\hline Naifs-HAART & $42(15.1)$ \\
\hline HAART-exposed & $237(84.9)$ \\
\hline \multicolumn{2}{|l|}{ HAART regimen, n (\%) } \\
\hline 2 NRTIs + 1NNRTIs & $205(86.5)$ \\
\hline $2 \mathrm{NRTIs}+1 \mathrm{IPs}$ & $32(13.5)$ \\
\hline Median duration of HAART exposure [Year (IQR)] & $3.5(2.2-9.7)$ \\
\hline $\mathrm{CD} 4$ rate $\left[\mathrm{cel} / \mathrm{mm}^{3}(\mathrm{IQR})\right]$ & $422(280-598)$ \\
\hline $\mathrm{CD} 4$ rate $\geq 500 \mathrm{cel} / \mathrm{mm}^{3}, \mathrm{n}(\%)$ & $101(39.3)$ \\
\hline Viral load suppressed, n (\%) & $181(80.8)$ \\
\hline
\end{tabular}

HAART: Highly active antiretroviral therapy; BMI: Body Mass Index; NNRTIs: Non-nucleoside reverse transcriptase inhibitors; NRTIs: Nucleoside reverse transcriptase inhibitors; IPs: Protease Inhibitors; SD: Standard deviation; IQR: Interquartile range.

All patients were infected with HIV1. Females were the most represented in a proportion of $71 \%$ with an M/F sex ratio of 0.4 . The mean age of the study population was 47.7 years $( \pm 9.3)$ with extremes of 25 and 72 years. The age range of 30 to 49.9 years accounted for $55.9 \%$. Eighty-four point two percent of the study population lived in urban areas. About half of the patients (49.5\%) were married, 
while widowed patients who had not remarried came second in $19 \%$ of the cases. Slightly less than half of the study population (46.2\%) lived from commerce followed by $12.2 \%$ from government employees. For $59.2 \%$ of the study population, the maximum level of study was primary. Alcohol addiction was found in $29.4 \%$ of cases and smoking was noted in $5 \%$ of cases. The median BMI was $23.3 \mathrm{~kg} / \mathrm{m}^{2}$ (IQR: 20.6 - 27.3) while $62.7 \%$ of the study population had a BMI $\geq 25 \mathrm{~kg} / \mathrm{m}^{2}$. The median CD4 count was 422 cells/ $\mathrm{mm}^{3}$ (IQR: 280 - 598) with $60.7 \%$ of patients with $\mathrm{CD} 4<500 \mathrm{cel} / \mathrm{mm}^{3}$. Eighty point eight percent of HAART-exposed patients had a suppressed viral load. The median duration of follow-up for HAART-exposed patients was 3.5 years (IQR: 2.3 - 9.7). Eighty-four point nine percent of patients were on a HAART combination of two Nucleoside Reverse Transcriptase Inhibitors (NRTIs) and a Non-Nucleoside Reverse Transcriptase Inhibitors (NNRTIs) and the remaining $15.1 \%$ were on a combination of two NRTIs and a Protease Inhibitor (PI). With Lamivudine as the common molecule in all combinations, the distribution of patients according to exposure to different HAART molecules was as follows: Tenofovir (92\%), Abacavir (7.2\%), Zidovudine $(0.8 \%)$, Efavirenz (86.1\%), Nevirapine (0.4\%), Atazanavir boosted with Ritonavir (12.2\%), Lopinavir boosted with Ritonavir (1.3\%). The remaining characteristics of the study population are presented in Table 1.

\subsection{Frequencies of the Metabolic Syndrome and Its Components}

Our study showed a prevalence of metabolic syndrome at $28.7 \%$. Abdominal obesity was the most represented component of MS with a proportion of $57.7 \%$ (5.4\% in men and $52.3 \%$ in women) of the cases, followed by $\mathrm{HCH}$ in $53.4 \%$ ( $10.0 \%$ in men and $43.4 \%$ in women) and high blood pressure (HBP) in $52.3 \%$ (Table 2).

Patients with metabolic syndrome had significantly a mean age, BMI and waist circumference higher than patients without. Similarly, they had higher

Table 2. Frequencies of metabolic syndrome and its components.

\begin{tabular}{cc}
\hline Variables & N (\%) \\
Abdominal Obesity & \\
Male $\geq 94 \mathrm{~cm}$ & $15(5.4)$ \\
Female $\geq 88 \mathrm{~cm}$ & $146(52.3)$ \\
Blood Pressure $\geq 130 / 85 \mathrm{mmhg}$ & $146(52.3)$ \\
HDL-Cholestérolemia & \\
Hommes $<40 \mathrm{mg} / \mathrm{l}$ & $28(10.0)$ \\
Femmes $<50 \mathrm{mg} / \mathrm{l}$ & $121(43.4)$ \\
Triglycéridemia $\geq 150 \mathrm{mg} / \mathrm{dl}$ & $34(12.2)$ \\
Glycemia $\geq 100 \mathrm{mg} / \mathrm{dl}$ & $53(19.0)$ \\
MS $(+)$ & $80(28.7)$ \\
\hline
\end{tabular}

MS: Metabolic Syndrome. 
median rates of HDLc, blood sugar, $\mathrm{PAS}, \mathrm{PAD}$, and CT/HDLc ratio than patients without metabolic syndrome (Table 3 ).

Table 3. Characteristics of patients according to metabolic syndrome.

\begin{tabular}{|c|c|c|c|}
\hline & MS (+) & MS (-) & p-value \\
\hline $\mathrm{N}(\%)$ & $80(28.7)$ & $199(71.3)$ & \\
\hline Age (Year), mean \pm SD & $49.4 \pm 9.5$ & $47.1 \pm 9.2$ & $<0.01$ \\
\hline Waist circumference $(\mathrm{cm})$, mean \pm SD & $93.9 \pm 10.0$ & $84.7 \pm 10.3$ & $<0.001$ \\
\hline $\mathrm{CT}(\mathrm{mg} / \mathrm{dl})$, mean $\pm \mathrm{SD}$ & $186.0 \pm 38.0$ & $179.0 \pm 46.0$ & NS \\
\hline HDLc [mg/dl (IQR)] & $43(37-47)$ & $50(43-58)$ & $<0.001$ \\
\hline $\mathrm{LDLc}[\mathrm{mg} / \mathrm{dl}(\mathrm{IQR})]$ & $120(98-141)$ & $112(84-130)$ & 0.018 \\
\hline $\mathrm{TG}[\mathrm{mg} / \mathrm{dl}(\mathrm{IQR})]$ & $99(66-153)$ & $86(62-113)$ & $<0.01$ \\
\hline Glycemia [mg/dl (IQR)] & $89(82-104)$ & $87(79-94)$ & $<0.01$ \\
\hline CT/HDLc Ratio (IQR) & $4.2(3.8-5.0)$ & $3.7(2.8-4.3)$ & $<0.001$ \\
\hline $\mathrm{SBP}[\mathrm{mmHg}(\mathrm{IQR})]$ & $140(131-154)$ & $123(113-134)$ & $<0.001$ \\
\hline $\mathrm{DBP}[\mathrm{mmHg}(\mathrm{IQR})]$ & $88(82-99)$ & $80(74-90)$ & $<0.001$ \\
\hline $\mathrm{BMI}\left[\mathrm{Kg} / \mathrm{m}^{2}(\mathrm{IQR})\right]$ & $26.9 \pm 4.6$ & $23.4 \pm 4.3$ & $<0.001$ \\
\hline Duration of HAART exposure [Year (IQR)] & $2.9(2.2-5.1)$ & $3.8(2.2-7.2)$ & NS \\
\hline \multicolumn{4}{|l|}{ Gender, n (\%) } \\
\hline Male & $12(15.0)$ & $69(34.7)$ & $<0.001$ \\
\hline Female & $68(85.0)$ & $130(65.3)$ & \\
\hline \multicolumn{4}{|l|}{ HAART exposure, n (\%) } \\
\hline Naifs-HAART & $10(12.5)$ & $69(34.7)$ & NS \\
\hline HAART-Exposed & $68(87.5)$ & $130(65.3)$ & \\
\hline \multicolumn{4}{|l|}{ Alcohol consumer, n (\%) } \\
\hline Yes & $59(73.8)$ & $138(69.3)$ & NS \\
\hline No & $21(26.2)$ & $61(30.7)$ & \\
\hline \multicolumn{4}{|l|}{ Smoker, n (\%) } \\
\hline Yes & $4(5.0)$ & $10(5.0)$ & NS \\
\hline No & $76(95.0)$ & $189(95.0)$ & \\
\hline \multicolumn{4}{|l|}{$\mathrm{BMI} \geq 25 \mathrm{Kg} / \mathrm{m}^{2}$} \\
\hline Yes & $45(63.4)$ & $59(28.4)$ & $<0.001$ \\
\hline No & $26(36.6)$ & $149(71.6)$ & \\
\hline \multicolumn{4}{|l|}{$\begin{array}{l}\text { HDLc }<40 \mathrm{mg} / \mathrm{l} \text { pour les hommes } \\
\text { et }<50 \mathrm{mg} / \mathrm{l} \mathrm{chez} \mathrm{les} \mathrm{femmes}\end{array}$} \\
\hline Yes & $71(88.8)$ & $78(39.2)$ & $<0.001$ \\
\hline No & $9(11.2)$ & $121(60.8)$ & \\
\hline \multicolumn{4}{|l|}{$\mathrm{TG} \geq 150 \mathrm{mg} / \mathrm{l}, \mathrm{n}(\%)$} \\
\hline Yes & $21(26.2)$ & $13(6.5)$ & $<0.001$ \\
\hline No & $59(73.8)$ & $186(93.5)$ & \\
\hline
\end{tabular}




\section{Continued}

Glycemia $\geq 100$ mg/l, n (\%)

$\begin{array}{llll}\text { Yes } & 27(33.8) & 26(13.1) & <0.001 \\ \text { No } & 53(66.2) & 173(86.9) & \end{array}$

LDLc $\geq 130$ mg/l, n (\%)

Yes

No

31 (38.8)

13 (6.5)

$49(61.3)$

$186(86.9)$

CT $\geq 200 \mathrm{mg} / \mathrm{l}, \mathrm{n}$ (\%)

Yes

No

$26(32.5)$

54 (67.5)

$148(74.4)$

NS

$\mathrm{CD} 4$ rate $\left(\mathrm{cel} / \mathrm{mm}^{3}\right), \mathrm{n}(\%)$

$<500$

$\geq 500$

Viral load, n (\%)

Suppressed

No Suppressed

HAART regimen, $\mathrm{n}(\%)$

$$
\text { 2NRTIs + 1NNRTIs }
$$

2INRTIs + 1IPs

CT/HDLc Ratio, n (\%)

BMI: Body Mass Index; CT: Total Cholesterol; DBP: Diastolic Blood Pressure; HAART: Highly active antiretroviral therapy; HDLc: HDL-Cholesterolemia; IQR: Interquartile range; LDLc: LDL Cholesterolemia; MS: Metabolic Syndrome; NNRTIs: Non-nucleoside reverse transcriptase inhibitors; NRTIs: Nucleoside reverse transcriptase inhibitors; NS: Not significant; IPs: Protease Inhibitors; SBP: Systolic Blood Pressure; SD: Standard deviation; TG: Triglyceridemia.

In bivariate analysis, the metabolic syndrome was associated with sex $(\mathrm{p}<$ $0.001)$, abdominal obesity $(\mathrm{p}<0.001)$, BMI $(\mathrm{p}<0.001)$, hyperglycemia $(\mathrm{p}<$ $0.05)$, HTG $(\mathrm{p}<0.001), \mathrm{HCH}(\mathrm{p}<0.001), \mathrm{HCL}(\mathrm{p}=0.011)$, risk of atherosclerosis as defined by the CT/HDL ratio $(\mathrm{p}=0.016)$ as well as CD4 count $(\mathrm{p}<0.028)$ (Table 3).

\subsection{Characteristics of the Components of the Metabolic Syndrome According to Patient's Exposure to HAART}

There was no significant difference between the frequency of MS in naive patients and HAART-exposed patients even though HAART-exposed patients presented more MS.

The MS components namely hyperglycemia and hypertension did not show statistically significant differences in the two groups of patients. However, our study objectified that patients exposed to HAART had a statistically higher frequency of abdominal obesity $(\mathrm{p}=0.014)$ compared to naive patients. Naive patients had a statistically higher frequency of HCL $(\mathrm{p}<0.01)$ and HTG $(\mathrm{p}=0.012)$ 
compared to HAART-exposed patients (Table 4).

\subsection{Study of the Components of the Metabolic Syndrome by Gender}

The frequency of metabolic syndrome was significantly higher in women ( $\mathrm{p}<$ $0.001)$ as well as abdominal obesity $(\mathrm{p}<0.001)$ and HCH $(\mathrm{p}<0.001)$. Men, on the other hand, had statistically higher frequencies of high blood pressure (HBP) $(\mathrm{p}=0.044)$ and HTG $(\mathrm{p}=0.039)$. There was no significant difference in the frequency of hyperglycemia between the two sexes (Table 5).

\subsection{Factors Associated with Metabolic Syndrome in Multivariate Analysis for Studied Variables}

In multivariate analysis, the female sex $(\mathrm{OR}=3.01$; CI: $1.52-5.93 ; \mathrm{p}<0.001)$, the $\mathrm{BMI} \geq 25 \mathrm{Kg} / \mathrm{m}^{2}$ (OR = 3.29; CI: $\left.1.92-5,64 ; \mathrm{p}<0.001\right)$, HCH (OR = 12.24; CI: 5.78 - 25.89; p < 0.001), HTG (OR = 5.09; CI: 2.40 - 10, 79; p < 0.01), Glyce$\mathrm{mia} \geq 100 \mathrm{mg} / \mathrm{l}(\mathrm{OR}=3.39$; CI: $1.82-6.30 ; \mathrm{p}<0.024), \mathrm{HCL}$ (OR = 2.04; CI: 1.17 - 3.56; $\mathrm{p}<0.012$ ), $\mathrm{CD} 4$ count $\geq 500 \mathrm{cel} / \mathrm{mm}^{3}$ (OR $=1.85$; CI: $1.06-3.20 ; \mathrm{p}<$ $0.029)$, HBP (OR = 13.04; CI: $6.16-27.62 ; \mathrm{p}<0.001)$, were associated with the presence of metabolic syndrome (Table 6).

Table 4. Characteristics of the components of the metabolic syndrome according to exposure to HAART.

\begin{tabular}{cccc}
\hline & Exposed N (\%) & Naifs N (\%) & p-value \\
\hline $\begin{array}{c}\text { Abdominal obesity } \\
\text { HDLc }(<40 \mathrm{mg} / \mathrm{l} \text { in men } \\
\text { and }<50 \mathrm{mg} / \mathrm{l} \text { in women })\end{array}$ & $144(60.8)$ & $17(40.5)$ & $\mathbf{0 . 0 1 4}$ \\
TG $\geq 150 \mathrm{mg} / \mathrm{l}$ & $118(49.8)$ & $31(73.8)$ & $\mathbf{0 . 0 0 5}$ \\
Glycemia $\geq 100 \mathrm{mg} / \mathrm{l}$ & $42(17.7)$ & $11(26.2)$ & $\mathbf{0 . 0 1 2}$ \\
BP $\geq 130 / 80 \mathrm{mmh}$ & $127(53.6)$ & $19(45.2)$ & NS \\
MS $(+)$ & $70(29.5)$ & $10(23.8)$ & NS \\
\hline
\end{tabular}

*Waist circumference $\geq 94 \mathrm{~cm}$ in men and $\geq 80 \mathrm{~cm}$ in women; BP: Blood Pressure; HDLc: HDL-Cholesterolemia; MS: Metabolic Syndrome; TG: Triglyceridemia; NS: Not Significant.

Table 5. Characteristics of the components of the metabolic syndrome according to sex.

\begin{tabular}{cccc}
\hline & Homme N (\%) & Femme N (\%) & p-value \\
\hline $\begin{array}{c}\text { Abdominal obesity* } \\
\text { HDLc }(<40 \mathrm{mg} / \mathrm{l} \text { in men } \\
\text { and }<50 \mathrm{mg} / \mathrm{l} \text { in women })\end{array}$ & $15(18.5)$ & $146(73.7)$ & $<0.001$ \\
$\mathrm{TG} \geq 150 \mathrm{mg} / \mathrm{l}$ & $28(34.6)$ & $121(61.1)$ & $<0.001$ \\
Glycemia $\geq 100 \mathrm{mg} / \mathrm{l}$ & $15(18.5)$ & $19(9.6)$ & $\mathbf{0 . 0 3 9}$ \\
$\mathrm{BP} \geq 130 / 80 \mathrm{mmh}$ & $21(25.9)$ & $32(16.2)$ & $\mathrm{NS}$ \\
$\mathrm{MS}(+)$ & $50(61.7)$ & $96(48.5)$ & $\mathbf{0 . 0 4 4}$ \\
\hline
\end{tabular}

*Waist circumference $\geq 94 \mathrm{~cm}$ in men and $\geq 80 \mathrm{~cm}$ in women; BP: Blood Pressure; HDLc: HDL-Cholesterolemia; MS: Metabolic Syndrome; TG: Triglyceridemia; NS: Not Significant. 
Table 6. Factors associated with metabolic syndrome according to the multivariate logistic regression model.

\begin{tabular}{|c|c|}
\hline & $\begin{array}{c}\text { MS (+) } \\
\text { Adjusted OR }(95 \% \text { CI) }\end{array}$ \\
\hline \multicolumn{2}{|l|}{ Gender } \\
\hline Male & 1 \\
\hline Female & $3.01(1.52-5.93)$ \\
\hline $\mathrm{p}$ & $<0.001$ \\
\hline \multicolumn{2}{|c|}{ Abdominal obesity* } \\
\hline No & 1 \\
\hline Yes & $9.55(4.52-20.17)$ \\
\hline $\mathrm{p}$ & $<0.001$ \\
\hline \multicolumn{2}{|c|}{ BMI $\left(\mathrm{Kg} / \mathrm{m}^{2}\right)$} \\
\hline$<25$ & 1 \\
\hline$\geq 25$ & $3.29(1.92-5.64)$ \\
\hline $\mathrm{p}$ & $<0.001$ \\
\hline \multicolumn{2}{|c|}{$\mathrm{HDLc}(<40 \mathrm{mg} / \mathrm{l}$ in men and $<50 \mathrm{mg} / \mathrm{l}$ in women) } \\
\hline No & 1 \\
\hline Yes & $12.24(5.8-25.89)$ \\
\hline $\mathrm{p}$ & $<0.001$ \\
\hline \multicolumn{2}{|c|}{$\mathrm{TG} \geq 150 \mathrm{mg} / \mathrm{l}$} \\
\hline No & 1 \\
\hline Yes & $5.09(2.40-10.79)$ \\
\hline $\mathrm{p}$ & $<0.001$ \\
\hline \multicolumn{2}{|c|}{ Glycemia $\geq 100 \mathrm{mg} / \mathrm{l}$} \\
\hline No & 1 \\
\hline Yes & $3.39(1.82-6.30)$ \\
\hline $\mathrm{p}$ & $<0.001$ \\
\hline \multicolumn{2}{|c|}{$\mathrm{LDLc} \geq 130 \mathrm{mg} / \mathrm{l}$} \\
\hline No & 1 \\
\hline Yes & $2.05(1.17-3.56)$ \\
\hline $\mathrm{p}$ & 0.012 \\
\hline \multicolumn{2}{|c|}{$\mathrm{BP} \geq 130 / 80 \mathrm{mmh}$} \\
\hline No & 1 \\
\hline Yes & $13.04(6.16-27.62)$ \\
\hline $\mathrm{p}$ & $<0.001$ \\
\hline \multicolumn{2}{|c|}{$\mathrm{CD} 4$ rate $\left(\mathrm{cel} / \mathrm{mm}^{3}\right)$} \\
\hline$<500$ & 1 \\
\hline$\geq 500$ & $1.85(1.06-3.20)$ \\
\hline $\mathrm{p}$ & 0.029 \\
\hline
\end{tabular}

*Waist circumference ( $\geq 90 \mathrm{~cm}$ Homme/ $\geq 80 \mathrm{~cm}$ Femme); BMI: Body Mass Index; BP: Blood Pressure; HDLc: HDL-Cholesterolemia; CI: Confidence Intervalle; MS: Metabolic Syndrome; LDLc: LDL-Cholesterolemia; OR: Odds Ratio; TG: Triglyceridemia. 


\section{Discussion}

Very few studies evaluating metabolic syndrome in PLWHIV on an African level remain available. In Togo, our study is the first to study the profile of the MS and its components in PLWHIV. The mean age of our study population was $47.73 \pm 9.3$ years with a predominance of patients aged 30 to 49.9 years which represented $55.9 \%$ of our sample. This result is consistent in studies of PLWHIV reflecting the economic impact of HIV infection on the young working population [11] [14] [15]. The female predominance highlighted in our study is also consistent in the literature reflecting the greater susceptibility of women to HIV infection than men [16] [17].

Our study allowed us to evaluate the prevalence of MS at $28.7 \%$ using the criteria of the Adult Treatment Panel III (ATPIII). At the level of the literature, the prevalence varies greatly depending on the authors and the definitions used for Metabolic Syndrome. In accordance with our result, Dimodi et al. in Cameroon [18], Katoto et al. in the Democratic Republic of Congo [17], Hansen et al. in Denmark [19] and Wu et al. in Taiwan [20] who used the criteria of ATPIII in their study reported respectively $30.7 \%, 27 \%, 27 \%$ and $26.2 \%$. However, our result remains lower than what has been reported by Muyandja et al. [21] and Obirikorang et al. [22] respectively $58 \%$ in Uganda and $48.7 \%$ in Ghana. Mbunkah et al. in Cameroon reported a prevalence lower than ours $18.03 \%$ [23]. However, our result falls within the estimated range of the prevalence of MS in the general population of PLWHIV [9] between 7\% and $45 \%$ and is slightly higher than the estimated prevalence in PLWHIV in sub-Saharan Africa namely 21.5\% [24]. The three most represented components of MS in our series were abdominal obesity, followed by $\mathrm{HCH}, \mathrm{HBP}$. Contrary to the data in the literature, where the dominant trio of the MS components are HTG, HCH and HBP [14] [16] [18], HTG is the component least represented in our study behind hyperglycemia whether the patient is exposed to HAART or naive. This low prevalence of HTG confirms a previous study that estimated HTG as the least frequent dyslipidemia among PLWHIV on HAART in the same proportions in Togo [11]. Tiozzo et al. nevertheless in their series found a predominance of abdominal obesity and HBP over HTG [15].

Our results show that patients with MS had significantly higher age, BMI, waist circumference, blood pressure, blood sugar, total cholesterol, HDLc, LDLc, triglycerides, and CT/HDLc ratio higher than patients without MS. Wu et al., Dimodi et al., Alvarez et al., achieved the same results [14] [18] [20].

We have highlighted a significant predominance of MS in women compared to men. Many authors have reached the same conclusion [18] [22]. However, Hansen et al. as well as Tiozzo et al. did not highlight in their series a significant difference in MS frequencies as a function of gender [15] [19]. This female predominance could be related to the predominance of women in the PLWHIV series. Nevertheless, studies have shown a predisposition of women to develop MS because of their biology, psychosocial factors and the environment [25]. 
We found that abdominal obesity and $\mathrm{HCH}$ were significantly more represented in women, while men were significantly more affected by HBP and HTG. Hyperglycemia did not show a significant difference between the two sexes. The frequencies of the components of MS according to gender are quite disparate than varied in the literature. Indeed, Dimodi et al. in Cameroon reported a high frequency of HBP in men but not of HTG which was rather high in women in addition to abdominal obesity [18]. In Ethiopia, Tesfaye et al. found the same result for women, but found no significant difference between the frequencies of hypertension compared to the two sexes [26]. Moreover, unlike us, he noted in his series a difference in the frequency of HTG between the two sexes [26].

Our study found a higher prevalence of MS in HAART-exposed patients compared to naive patients $(29.5 \%$ vs $23.8 \%)$ with no significant statistical difference. If numerous studies have objectified a significant predominance of MS in exposed subjects [18] [22] [23] [27], our result could be linked to the small proportion of naive patients in our sample (15.1\%). Our study, for example, did not show any association between duration on HAART and MS confirming the conclusions of some authors [26] [28] [29]. It should be noted, however, that other authors have reported the existence of an association between the duration of exposure to HAART and MS in PLWHIV on HAART [14] [16] [20]. The exact contribution of HAART in MS remains unclear because if the involvement of HAART in metabolic disturbances involving the components of MS is well documented [3] [30], the question arises as to whether the high rates of MS in HAART-exposed individuals are related to the duration of therapy or rather to the fact that these patients are older than naive [9]. Waist circumference was significantly higher in HAART patients compared to naive patients when the latter had more $\mathrm{HCH}$ and HTG. This result is similar to those reported by Jacobson et al. and Tesfaye et al. [26] [31]. In contrast, Dimodi et al. reported in their series a predominance of HCH and HTG in HAART-exposed patients [18]. These differences could be explained in the anti-retroviral treatment profiles used by the patients but also in the particularities of the different ethnic groups making up the study populations.

Age, smoking, and alcohol addiction were not associated with MS in our study. With regard to age, our result contrasts with that of Elgalib et al. [32] and of Mbunkah et al. [23]. Alavarez et al. reported the lack of association between MS and smoking [14]. However, Alencastro et al. reported an association between MS, alcohol addiction and smoking [33].

The ongoing HAART lines in HAART-exposed patients were not associated with MS. Our result is in line with those reported by Samara et al. [29], Tesfaye et al. [26]. In contrast Dimodi et al., Tiozzo et al., Obirikorang et al. reported the existence of an association between ARV treatment and MS [15] [18] [22].

Our study allowed us to identify as risk factors associated with MS, all the components of MS, the female sex, CD4 count $\geq 500 \mathrm{cel} / \mathrm{mm}^{3}, \mathrm{BMI} \geq 25 \mathrm{~kg} / \mathrm{m}^{2}$. This result confirms the findings of Mbunkah et al., Dimodi et al. [18] [23]. Elsewhere, age has been reported as a risk factor by Tesfaye et al. [26] while Tes- 
faye et al. and Bosho et al. did not report sex as a risk factor [16] [26].

\section{Conclusion}

MS is a reality in Togo among PLWHIV. With a prevalence of $28.7 \%$, it is above its estimated prevalence in sub-Saharan Africa. The duration of HAART exposure and the HAART lines were not associated with MS in exposed patients. Factors associated with MS were all components of metabolic syndrome, female gender, $\mathrm{CD} 4$ count $\geq 500$ cells $/ \mathrm{mm}^{3}, \mathrm{BMI} \geq 25 \mathrm{~kg} / \mathrm{m}^{2}$. In order to reduce the risk of cardiovascular complications in PLWHA, it is necessary to include in their follow-up a screening of MS risk factors for early detection and treatment.

\section{Conflicts of Interest}

We announce that we have no competing interests.

\section{References}

[1] HIV/AIDS (n.d.). https://www.who.int/news-room/fact-sheets/detail/hiv-aids

[2] (n.d.) Global HIV \& AIDS Statistics-2019 Fact Sheet. https://www.unaids.org/en/resources/fact-sheet

[3] Masuku, S.K., Tsoka-Gwegweni, J. and Sartorius, B. (2019) HIV and Antiretroviral Therapy-Induced Metabolic Syndrome in People Living with HIV and Its Implications for Care: A Critical Review. Journal of Diabetology, 10, 41-47. https://doi.org/10.4103/jod.jod_21_18

[4] Caballero, A.E. (2004) Endothelial Dysfunction, Inflammation, and Insulin Resistance: A Focus on Subjects at Risk for Type 2 Diabetes. Current Diabetes Reports, 4 , 237-246. https://doi.org/10.1007/s11892-004-0074-9

[5] Dooko, C.B.A., Wit, S.D., Neuhaus, J., Palfreeman, A., Pepe, R., Pankow, J.S., et al. (2014) Interleu-kin-6, High Sensitivity C-Reactive Protein, and the Development of Type 2 Diabetes among HIV-Positive Patients Taking Antiretroviral Therapy. Journal of Acquired Immune Deficiency Syndromes, 67, 538-546. https://doi.org/10.1097/QAI.0000000000000354

[6] De Larrañaga, G., Petroni, A., Deluchi, G., Alonso, B. and Benetucci, J. (2003) Viral Load and Disease Progression as Responsible for Endothelial Activation and/or Injury in Human Immunodeficiency Virus-1-Infected Patients. Blood Coagulation \& Fibrinolysis. An International Journal in Haemostasis and Thrombosis, 14, 15-18. https://doi.org/10.1097/00001721-200301000-00004

[7] Harrington, L., Hatton, R., Mangan, P., Turner, H., Murphy, T., Murphy, K., et al. (2005) Interleukin 17-Producing CD4+ Effector T Cells Develop via a Lineage Distinct from the T Helper Type 1 and 2 Lineages. Nature Immunology, 6, 1123-1132. https://doi.org/10.1038/ni1254

[8] Carr, M.C. and Brunzell, J.D. (2004) Abdominal Obesity and Dyslipidemia in the Metabolic Syndrome: Importance of Type 2 Diabetes and Familial Combined Hyperlipidemia in Coronary Artery Disease Risk. The Journal of Clinical Endocrinology \& Metabolism, 89, 2601-2607. https://doi.org/10.1210/jc.2004-0432

[9] Worm, S.W. and Lundgren, J.D. (2011) The Metabolic Syndrome in HIV. Best Practice \& Research Clinical Endocrinology \& Metabolism, 25, 479-486. https://doi.org/10.1016/j.beem.2010.10.018 
[10] Togo (n.d.). https://www.unaids.org/fr/regionscountries/countries/togo

[11] Moukaila, A.R., Bawe, L.D., Mossi, E.K., Patassi, A.A., Tsevi, Y.M., Nemi, K.D., et al. (2019) Dyslipidemia in People Living with HIV on Anti-Retroviral Treatment: Case of the Ambulatory Treatment Center (ATC) of the Sylvanus Olympio University Hospital of Lome. Open Journal of Internal Medicine, 9, 141-157. https://doi.org/10.4236/ojim.2019.94019

[12] Alberti, K.G.M.M., Eckel, R.H., Grundy, S.M., Zimmet, P.Z., Cleeman, J.I., Donato, K.A., et al. (2009) Harmonizing the Metabolic Syndrome: A Joint Interim Statement of the International Diabetes Federation Task Force on Epidemiology and Prevention; National Heart, Lung, and Blood Institute; American Heart Association; World Heart Federation; International Atherosclerosis Society; and International Association for the Study of Obesity. Circulation, 120, 1640-1645. https://doi.org/10.1161/CIRCULATIONAHA.109.192644

[13] Samaras, K., Wand, H., Law, M., Emery, S., Cooper, D. and Carr, A. (2007) Prevalence of Metabolic Syndrome in HIV-Infected Patients Receiving Highly Active Antiretroviral Therapy Using International Diabetes Foundation and Adult Treatment Panel III Criteria: Associations with Insulin Resistance, Disturbed Body Fat Compartmentalization, Elevated C-Reactive Protein, and [Corrected] Hypoadiponectinemia. Diabetes Care, 30, 113-119. https://doi.org/10.2337/dc06-1075

[14] Alvarez, C., Salazar, R., Galindez, J., Rangel, F., Lopardo, G., et al. (2010) Metabolic Syndrome in HIV-Infected Patients Receiving Antiretroviral Therapy in Latin America. Brazilian Journal of Infectious Diseases, 14, 256-263. https://doi.org/10.1016/S1413-8670(10)70053-2

[15] Tiozzo, E., Konefal, J., Adwan, S., Martinez, L.A., Villabona, J., Lopez, J., et al. (2015) A Cross-Sectional Assessment of Metabolic Syndrome in HIV-Infected People of Low Socio-Economic Status Receiving Antiretroviral Therapy. Diabetology \& Metabolic Syndrome, 7, 15. https://doi.org/10.1186/s13098-015-0008-5

[16] Bosho, D.D., Dube, L., Mega, T.A., Adare, D.A., Tesfaye, M.G. and Eshetie, T.C. (2018) Prevalence and Predictors of Metabolic Syndrome among People Living with Human Immunodeficiency Virus (PLWHIV). Diabetology \& Metabolic Syndrome, 10, 10. https://doi.org/10.1186/s13098-018-0312-y

[17] Katoto, P.D.M.C., Thienemann, F., Bulabula, A.N.H., Esterhuizen, T.M., Murhula, A.B., Lunjwire, P.P.M., et al. (2018) Prevalence and Risk Factors of Metabolic Syndrome in HIV-Infected Adults at Three Urban Clinics in a Post-Conflict Setting, Eastern Democratic Republic of the Congo. Tropical Medicine \& International Health, 23, 795-805. https://doi.org/10.1111/tmi.13073

[18] Dimodi, H.T., Etame, L.S., Nguimkeng, B.S., Mbappe, F.E., Ndoe, N.E., Tchinda, J.N., et al. (2014) Prevalence of Metabolic Syndrome in HIV-Infected Cameroonian Patients. World Journal of AIDS, 4, 85-92. https://doi.org/10.4236/wja.2014.41011

[19] Hansen, B.R., Petersen, J., Haugaard, S.B., Madsbad, S., Obel, N., Suzuki, Y., et al. (2009) The Prevalence of Metabolic Syndrome in Danish Patients with HIV Infection: The Effect of Antiretroviral Therapy. HIV Medicine, 10, 378-387. https://doi.org/10.1111/j.1468-1293.2009.00697.x

[20] Wu, P.-Y., Hung, C.-C., Liu, W.-C., Hsieh, C.-Y., Sun, H.-Y., Lu, C.-L., et al. (2012) Metabolic Syndrome among HIV-Infected Taiwanese Patients in the Era of Highly Active Antiretroviral Therapy: Prevalence and Associated Factors. The Journal of Antimicrobial Chemotherapy, 67, 1001-1009. https://doi.org/10.1093/jac/dkr558

[21] Muyanja, D., Muzoora, C., Muyingo, A., Muyindike, W. and Siedner, M.J. (2016) High Prevalence of Metabolic Syndrome and Cardiovascular Disease Risk among 
People with HIV on Stable ART in Southwestern Uganda. AIDS Patient Care and STDs, 30, 4-10. https://doi.org/10.1089/apc.2015.0213

[22] Obirikorang, C., Quaye, L., Osei-Yeboah, J., Odame, E.A. and Asare, I. (2016) Prevalence of Metabolic Syndrome among HIV-Infected Patients in Ghana: A Cross-Sectional Study. Nigerian Medical Journal: Journal of the Nigeria Medical Association, 57, 86-90. https://doi.org/10.4103/0300-1652.182082

[23] Mbunkah, H., Meriki, H., Anthony Tufon, K., Nfor, O. and Nkuo-Akenji, T. (2014) Prevalence of Metabolic Syndrome in Human Immunodeficiency Virus-Infected Patients from the South-West Region of Cameroon, Using the Adult Treatment Panel III Criteria. Diabetology \& Metabolic Syndrome, 6, 92. https://doi.org/10.1186/1758-5996-6-92

[24] Todowede, O.O., Mianda, S.Z. and Sartorius, B. (2019) Prevalence of Metabolic Syndrome among HIV-Positive and HIV-Negative Populations in Sub-Saharan Africa-A Systematic Review and Meta-Analysis. Systematic Reviews, 8, 4. https://doi.org/10.1186/s13643-018-0927-y

[25] Villamar, M.F., Albuja, A.C. and Salas, N.I. (2011) Metabolic Syndrome among HIV-Infected Out-Patients from a Hospital in Quito, Ecuador: A Cross Sectionnal Study. Revista Panamericana Infectologia, 13, 12-18.

[26] Tesfaye, D.Y., Kinde, S., Medhin, G., Megerssa, Y.C., Tadewos, A., Tadesse, E., et al. (2014) Burden of Metabolic Syndrome among HIV-Infected Patients in Southern Ethiopia. Diabetes \& Metabolic Syndrome: Clinical Research \& Reviews, 8, 102-107. https://doi.org/10.1016/j.dsx.2014.04.008

[27] Krishnan, S., Schouten, J., Atkinson, B., Brown, T., Wohl, D., McComsey, G., et al. (2012) Metabolic Syndrome before and after Initiation of Antiretroviral Therapy in Treatment-Naive HIV-Infected Individuals. Journal of Acquired Immune Deficiency Syndromes (1999), 61, 381-389. https://doi.org/10.1097/QAI.0b013e3182690e3c

[28] Mondy, K., Overton, E.T., Grubb, J., Tong, S., Seyfried, W., Powderly, W., et al. (2007) Metabolic Syndrome in HIV-Infected Patients from an Urban, Midwestern US Outpatient Population. Clinical Infectious Diseases. An Official Publication of the Infectious Diseases Society of America, 44, 726-734. https://doi.org/10.1086/511679

[29] Samaras, K. (2009) Prevalence and Pathogenesis of Diabetes Mellitus in HIV-1 Infection Treated with Combined Antiretroviral Therapy. JAIDS Journal of Acquired Immune Deficiency Syndromes, 50, 499. https://doi.org/10.1097/QAI.0b013e31819c291b

[30] Dau, B. and Holodniy, M. (2008) The Relationship between HIV Infection and Cardiovascular Disease. Current cardiology Reviews, 4, 203-218. https://doi.org/10.2174/157340308785160589

[31] Jacobson, D., Tang, A., Spiegelman, D., Thomas, A., Skinner, S. and Wanke, C. (2007) Incidence of Metabolic Syndrome in a Cohort of HIV-Infected Adults and Prevalence Relative to the US Population (National Health and Nutrition Examination Survey). Journal of Acquired Immune Deficiency Syndromes (1999), 43, 458-466. https://doi.org/10.1097/01.qai.0000243093.34652.41

[32] Elgalib, A., Aboud, M., Kulasegaram, R., Dimian, C., Duncan, A., Wierzbicki, A.S., et al. (2011) The Assessment of Metabolic Syndrome in UK Patients with HIV Using Two Different Definitions: CREATE 2 Study. Current Medical Research and Opinion, 27, 63-69. https://doi.org/10.1185/03007995.2010.537212

[33] Alencastro, P.R., Wolff, F.H., Oliveira, R.R., Ikeda, M.L.R., Barcellos, N.T., Brandão, 
A.B.M., et al. (2009) Metabolic Syndrome and Population Attributable Risk among HIV/AIDS Patients: Comparison between NCEP-ATPIII, IDF and AHA/NHLBI Definitions. AIDS Research and Therapy, 9, 29.

https://doi.org/10.1186/1742-6405-9-29 